\title{
¡Por fin, paz en la Tierra!'
}

Federico Mayor Zaragoza

Recibido 28.01.2015 / Aceptado: 10.02.2015

"El tiempo del silencio, de la imposición y del miedo ha concluido"

\section{RESUMEN}

En este artículo de suprema importancia, Federico Mayor Zaragoza, de manera fundamentada señala los factores o condiciones, que por vez primera representan un punto de inflexión para el tránsito de la humanidad, de la cultura de la imposición y dominación a la cultura del encuentro y de la paz. Nos brinda información de las grandes oportunidades perdidas, luego de la primera y segunda guerras mundiales y del fin de la guerra fría.

En la era digital, tan reciente, tan consolidada ya, no sólo conocemos en tiempo real "la vida en la Tierra", sino que podemos transmitir nuestros pensamientos y emociones, podemos participar en los asuntos del estado, nación y el mundo.

Por eso es preciso que ahora, cuando ya podemos expresarnos, cuando ya las mujeres participan progresiva y activamente en la toma de decisiones, cuando ya todos los seres humanos y no unos cuantos pueden manifestarse y actuar en virtud de sus propias reflexiones, sea el clamor popular, la voz del pueblo, de "Nosotros, los pueblos...", el que haga posible el advenimiento del "nuevo comienzo", que con tanta lucidez preconiza la Carta de la Tierra.

Palabras clave: paz, nuevo comienzo, transición, humanidad, democracia.

\section{ABSTRACT}

Federico Mayor Zaragoza, in this article of supreme importance, in a reasoned manner, indicates the factors or conditions that, for the first time represent a turning point for the path of humankind, from a culture of imposition and domination to a culture of encounter and peace. It provides information of dismissed opportunities after the first and second world wars and the end of the Cold War.

In the digital era a very recent era but already a wellestablished one, we are not only able to approach "life on Earth" in real time, but also convey our thoughts and emotions. We can now participate in the affairs of the state, nation and the world.

It is essential today, when we can finally express ourselves, when women are gradually and actively participating in decision-making, when all human beings and not only a few can demonstrate and act according to their own reflections, that the public outcry, the voice of the people, "We, the peoples..." become the driving force for the advent of a "new beginning," as clearly advocated by the "Earth Charter".

Key words: peace, new beginning, transition, humankind

1 "Por fin, paz en la Tierra" publicado en el Anuario 2014-2015: "Focos de tensión, cambio geopolítico y agenda global" editado por CEIPAZ- Fundación Cultura de Paz.

2 Presidente de la Fundación Cultura de Paz 


\section{Por primera vez en la historia, la inflexión de la fuerza a la palabra es posible}

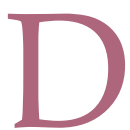
esde el origen de los tiempos, los seres humanos han vivido territorial e intelectualmente en espacios muy limitados, en los que nacían, vivían y morían. Eran seres invisibles, anónimos, atemorizados, que no podían expresarse más allá de su entorno inmediato, y que, por otra parte, desconocían en buena medida las características y proporciones de lo que sucedía en el mundo...

Eran espectadores impasibles. Sin embargo, eran los "ojos del Universo", los únicos seres vivos capaces de pensar, de tener conciencia refleja, de saber, de imaginar, de crear. Fugaces, pero dotados de unas cualidades distintivas extraordinarias que debían aplicar en ámbitos muy restringidos. De vez en cuando, un gran destello filosófico, artístico, para después volver a ser inaparentes, súbditos. Toda la historia durante siglos $\mathrm{y}$ siglos se ha reducido a acontecimientos que han tenido lugar en tiempo y espacio desconocidos. Lo que aconteció en muchos lugares de la Tierra se ha deducido después, fruto de estudios retrospectivos, al conocerla en su conjunto.

Lo cierto es que hasta hace muy pocas décadas, en la transición de la vida rural a urbana se habían producido cambios sustanciales sociales, sanitarios, económicos, políticos, pero el poder seguía estando en manos de muy pocos hombres que dominaban al resto de hombres y al conjunto de las mujeres. Todo se resolvía por la fuerza.

"Si vis pacem, para bellum", era el adagio que se aplicaba inexorablemente. A mediados del siglo pasado, a pesar de haberse producido considerables progresos, la inmensa mayoría de los habitantes de la Tierra no habían podido adquirir la categoría de ciudadanos plenos, de ciudadanos del mundo "liberados del miedo", como se proclama en el Preámbulo de la Declaración Universal de los Derechos Humanos adoptada por la Asamblea General de las Naciones Unidas en el año 1948: “Estos derechos humanos son para liberar a la humanidad del miedo"...

Pero, acto seguido, silencio de los silenciados, silencio de los silenciosos. Unos porque no podían hablar, porque se hallaban amordazados por la ignorancia o por un sistema de libertades nulas. Otros porque, pudiendo expresarse, no osaban hacerlo. "La voz que pudo ser remedio y por miedo no fue nada". De pronto, hace dos décadas, la voz. De pronto, la palabra. Se trata de una inflexión histórica: todos los seres humanos pueden, progresivamente, manifestar sus puntos de vista gracias a la moderna tecnología de la comunicación y de la información. En la era digital, tan reciente, tan consolidada ya, no sólo conocemos en tiempo real "la vida en la Tierra", sino que podemos transmitir nuestros pensamientos y emociones, podemos participar...

Piedra angular de la nueva era son las mujeres, subordinadas durante siglos por el poder masculino y que, cuando por razones dinásticas, normalmente aparecían en los escenarios del poder, actuaban, lógicamente, de forma mimética. Ahora, en cambio, la igualdad de género es un objetivo fundamental para los cambios radicales que la igual dignidad de todos los seres humanos exige. ¡La igual dignidad! Este es el fundamento de todos los derechos humanos, esta es la base de la construcción de la nueva convivencia. Sea cual sea la edad, el color de piel, la religión, la ideología, el sexo... todos iguales en dignidad. Por primera vez, por tanto, es posible la gran transición de una cultura de imposición, dominio, violencia y guerra a una cultura de encuentro, conversación, conciliación, alianza y paz (Naciones Unidas, 1999). No es admisible que mueran de hambre diariamente más de 30.000 personas, la mayor parte de ellas niños y niñas de uno a cinco años, al tiempo que se invierten en armas y gastos militares 3.000 millones de dólares. No es admisible que, según un informe reciente de OXFAM (2014), 85 personas posean una riqueza mayor que la mitad de la humanidad, un equivalente a 3.300 millones de seres humanos.

La cultura de paz y no violencia es una exigencia apremiante para el diseño del porvenir, para que tantos 
imposibles hoy se hagan realidad mañana. "Ningún desafío al que tenemos que hacer frente se sitúa más allá de la capacidad creadora que es inherente de la especie humana". Esta es nuestra esperanza. Cada ser humano es único y capaz de crear. La frase de Kennedy, pronunciada pocos meses antes de que fuera asesinado, es para mí una especie de "ritornello" para superar la debacle ética actual, la crisis sistémica que estamos atravesando, la deriva de una economía neoliberal que todo lo basa, exclusivamente, en el dinero, hasta el punto de que en Europa, en el año 2003, se acordó una Unión monetaria sin Unión política y económica previas. ¡Qué disparate! Por eso es preciso que ahora, cuando ya podemos expresarnos, cuando ya las mujeres participan progresiva y activamente en la toma de decisiones, cuando ya todos los seres humanos y no unos cuantos pueden manifestarse y actuar en virtud de sus propias reflexiones, sea el clamor popular, la voz del pueblo, de "Nosotros, los pueblos..." (Naciones Unidas, 1945), el que haga posible el advenimiento del "nuevo comienzo" que con tanta lucidez preconiza la Carta de la Tierra (2000).

\section{Una movilización liderada por la comunidad científica, académica y artística}

Sólo la participación ciudadana permitirá una democracia genuina. Porque, actualmente, en las urnas, en los comicios electorales se cuenta a los ciudadanos pero luego no son tenidos en cuenta, no cuentan de forma permanente, que en esto consiste la auténtica democracia. Ahora ya no será posible desoír el clamor popular. Ya no será posible mirar hacia otro lado, porque miles, millones de voces reclamarán atención hacia aquellas acciones y medidas que consideren más apropiadas.

Porfin, el poderciudadanovaa sustituir el ya mencionado "Si vispacem, para bellum" por el referente que marcará la nueva era: "Si vis pacem, para verbum". La gran transición será de la fuerza a la palabra, de la imposición a la conversación. Actualmente, en nuestr propio país estamos presenciando una total supeditación del poder Legislativo al Ejecutivo, debido a la mayoría parlamentaria absoluta de que dispone el gobierno. Y así se aprueban leyes, incluso en temas esenciales como la educación y la seguridad, sin tener en cuenta a todos los ciudadanos que se hallan representados por otros partidos políticos o, sencillamente, no se hallan representados en el Parlamento.

No se escucha a los pueblos, no se escuchan sus deseos y propuestas. La democracia se convierte en una herramienta a favor de los que mandan. Es lamentable que, recientemente, se hayan adoptado medidas, normas y hasta leyes, fruto de mayorías parlamentarias absolutas, que afectan directamente el buen ejercicio de los derechos humanos. En este campo, se sitúa también el haber suprimido el ejercicio de la justicia universal, cuando ahora ya los pueblos -véase la "primavera árabe", tan eficiente como descarrilada en algunos casosson capaces de alzar la voz. Voz tantos años aguardada que demuestra el amanecer del poder ciudadano.

La subordinación de los políticos a los mercados ha llegado al punto de tener la desfachatez de designar sin comicios a los gobiernos de Italia y de Grecia, cuna de la democracia, porque los valores bursátiles han marginado a los valores éticos y el multilateralismo democrático ha sido sustituido por grupos plutocráticos de siete, ocho o 20 países prósperos. ¿Cómo se puede pretender que unos cuantos países impongan sus designios a más de 190 países que hoy figuran en las Naciones Unidas?

Jeffrey Sachs, en un interesante artículo sobre la comprensión y superación de la plutocracia en América, pone de manifiesto que, los norteamericanos más ricos están trabajando "para los más ricos de los ricos. No hay precedentes de tiempos mejores para el $1 \%$ más acaudalado" (Sachs, 2014). Habla a continuación de los "mega-lobbies" de gigantes del petróleo, la defensa, los seguros médicos y la industria farmacéutica. En las últimas elecciones parciales, los multimillonarios y sus empresas contribuyeron a recaudar un total de más de 3.600 millones de dólares para las distintas candidaturas. La plutocracia se difunde como una epidemia hasta que la democracia decae y se 
Omar d’León

desvanece. La historia muestra muchas que no se atenta contra las democracias desde fuera sino desde dentro.

Hasta ahora no era posible expresar disentimiento más que a través de concentraciones presenciales que, con frecuencia, implicaban el uso de la violencia. Ahora, con el ciberespacio, el poder ciudadano podrá influir decisivamente en la política, en la definición de objetivos, en la adopción de medidas (Mayor, 2011a). Podrá canalizar alternativas y cambios de paradigma. Gradualmente, a veces imperceptiblemente, se derribarán muros, se abrirán puertas, se construirán puentes, se anudarán lazos de amistad para una convivencia que ya no estará enmarcada en inalterables e intransitables confines si no que dará lugar, en el ámbito ético, político, social y cultural, a transformaciones de hondo calado. Paulatinamente, una multiplicidad de factores producirá un "cambio de actitud" personal, de ciudadanos libres convencidos de que hay que hallar nuevos caminos y disponer de nuevas brújulas (Mayor, 2012a).

\section{Desde hace un siglo, tres oportunidades de paz desechadas}

En las tres ocasiones, ha sido el Partido Republicano de los Estados Unidos el que, por ambiciones hegemónicas, ha impedido que las iniciativas de paz llegaran a buen puerto. La primera ocasión, como he subrayado varias veces, fue a principios del año 1919. El Presidente Wilson había llegado desde Nueva York a Brest, horrorizado por aquella terrible guerra de extenuación, llevando un mensaje de paz al mundo: la "Convención para la Paz Permanente" permitiría que los conflictos se resolvieran a través de una Sociedad o Liga de Naciones, que tendría su sede en Ginebra. Simultáneamente se crearía la Corte Internacional de Justicia Permanente. La reacción de su propio país no se hizo esperar: el Presidente no se había elegido para que fuera campeón de paz sino para que fuera campeón de guerra.

Y la prohibición llegó hasta tal punto que los Estados Unidos -iinmensa contradicción que tenemos que tener en cuenta desde un punto de vista histórico!- no maron parte de la Sociedad de Naciones ue el propio Presidente norteamericano había creado. Lo que sucedió ya es conocido. Alemania se rearmó, el nazismo y el fascismo adquirieron maneras dictatoriales y en el año 1939 estalló la Segunda Guerra Mundial.

Fue una confrontación terrible, con holocausto, genocidio, con un desprecio total a las pautas básicas humanitarias que alivian las facetas más horrendas de los conflictos bélicos. A Alemania e Italia se les unió el Imperio del Sol Naciente que, culminando el insólito y ambicioso "Plan Tanaka", atacó a la Armada de los Estados Unidos en Pearl Harbour en el mes de diciembre de 1941. En 1944, cuando ya se vislumbraba el fin de la Segunda Guerra Mundial, el Presidente Roosevelt hizo un gran diseño para la paz mundial: la ayuda a los vencidos, con el Plan Marshall; la regulación monetaria con el FMI; financiación para la reconstrucción y el desarrollo por el Banco Mundial y la creación de las agencias internacionales que, por su especialidad, podían ser muy eficaces para las Naciones Unidas: la alimentación (FAO); la educación, la ciencia y la cultura (UNESCO); la salud (OMS); el trabajo (OIT); el fomento del desarrollo (PNUD); protección a la infancia (Fondo UNICEF)...

Tanto en la redacción de la Carta de las Naciones Unidas como en la Constitución de la UNESCO, su rama intelectual, intervienen pensadores de una gran clarividencia ética y política. La Carta de las Naciones Unidas se inicia diciendo que "Nosotros, los pueblos... hemos resuelto evitar a las generaciones venideras el horror de la guerra". En esta frase se condensan las soluciones que hoy reclama el mundo en su conjunto, porque podrían afrontar eficazmente los gravísimos desafíos presentes. En efecto, son los pueblos los que toman en sus manos las riendas del destino común. Y lo hacen comprometidos con las generaciones venideras, con esta responsabilidad que hoy constituye una de las más graves carencias de la acción política internacional. Y van a construir la paz, porque para evitar la guerra intentarán, a través de las Naciones Unidas, la resolución pacífica de los conflictos; la utilización de la diplomacia, del encuentro, de la conciliación, entre otras tareas. 
Pronto no fueron "los pueblos" sino los Estados únicamente los que constituyeron la Asamblea General; pronto los países vencedores encabezados por Estados Unidos sustituyeron el voto por el veto y la cooperación internacional -el verbo "compartir" era la palabra clave para un nuevo futuro- por la explotación. Otra gran ocasión frustrada, porque la Declaración Universal de los Derechos Humanos (1948), ponía de manifiesto los referentes luminosos para guiar adecuadamente a la humanidad en su conjunto hacia una nueva era en que se hiciera realidad la raíz y cimiento de los mismos: la igual dignidad de todos los seres humanos.

Así, como ya se ha mencionado al principio, el Preámbulo de la Declaración señala que los derechos humanos son "para liberar a la humanidad del miedo". Con la carrera armamentística entre las superpotencias, los Estados Unidos y la Unión Soviética, el miedo no decreció sino que se incrementó, y los gastos militares y la producción de artificios bélicos cada vez más potentes ocuparon aquellos años en los que, si se hubiera desarrollado el Sistema de las Naciones Unidas guiado por los principios democráticos que establece la Constitución de la UNESCO, los muros se hubieran derribado y se hubieran construido puentes de entendimiento y amistad entre todos los países de la Tierra.

La tercera oportunidad, malograda también por el Partido Republicano de Estados Unidos, con el Reino Unido como acólito, se produce precisamente al final de la Guerra Fría. En 1989, cuando todo clamaba paz, cuando la Unión Soviética se había transformado, por el arte de Mikhail S. Gorbachev, en una Comunidad de Estados Independientes que iniciaban su larga marcha hacia las libertades públicas; cuando el apartheid racial se había superado gracias a la magia extraordinaria de un prisionero que abandonó su cautiverio con los brazos abiertos y que en lugar de gritar venganza, gritó y consiguió la reconciliación y el perdón; cuando se alcanzaba la paz en Mozambique y en El Salvador y se reiniciaba el Proceso de Paz en Guatemala, entre otros acontecimientos.

En un momento en que todo clamaba paz, el Presidente Reagan y la Primer Ministro Margaret Thatcher ponen en marcha el sistema neoliberal globalizador, en el cual los principios democráticos se sustituyen por las leyes del mercado y las Naciones Unidas por grupos plutocráticos.
En pocos años, se produce una auténtica debacle ética y económica. Los mercados se hacen dueños de la situación y acosan y marginan al poder político. El resultado es la desigualdad, la miseria, el armamentismo, el deterioro del medio ambiente, miles de muertos diariamente de hambre que son considerados "efectos colaterales" de un sistema que hace más pobres a los pobres y más ricos a los ricos. En cifras de balance, debemos reiterarlo con firmeza y con propósito de enmienda, cada día miles de millones de dólares en armas y gastos militares al tiempo que mueren de hambre miles y miles de personas.

Y las desigualdades se acrecientan debido a la incorporación de los partidos de centro-izquierda al esquema neoliberal liderado por el gran capital.

\section{Transiciones impensables hace unos años y posibles en la actualidad}

Ahora será el poder ciudadano el que, en pocos años, impulse la transición desde una economía de especulación, deslocalización productiva y de guerra a una economía de desarrollo global sostenible y humano, basada en el conocimiento, y que tenga en cuenta los cambios que en las características propias del trabajo y del empleo han producido la mecanización, robotización $\mathrm{y}$, en general, la tecnología digital.

Transición de una cultura de imposición, violencia y guerra a una cultura de conciliación, comprensión, alianza y paz. La Declaración y Programa de Acción sobre una Cultura de Paz que se aprobó en la Asamblea General de las Naciones Unidas, en septiembre de 1999, es el nuevo cauce por el que, sin duda, discurrirá la humanidad en el "nuevo comienzo". Transición de súbditos a ciudadanos, apareciendo el mundo nuevo que resultaría de los cuatro "Contratos" que propuse, al final del desempeño de la Dirección General de la UNESCO en el año 2000: un nuevo contrato social; un nuevo contrato natural; un nuevo contrato cultural; y un nuevo contrato ético (Mayor, 2000).

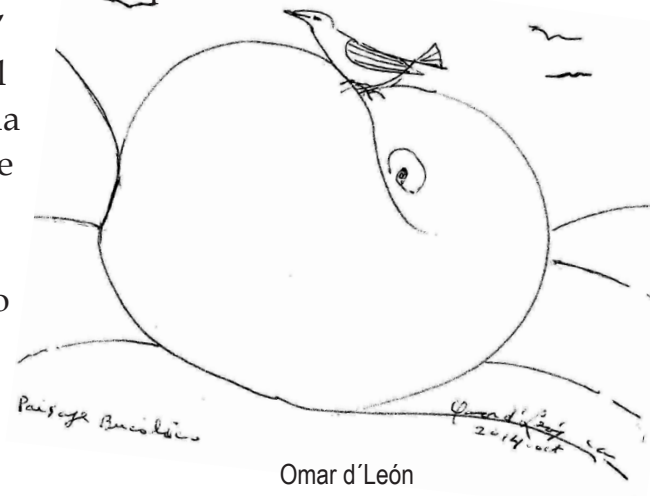


En la transición de súbditos a ciudadanos es indispensable la capacidad de diálogo que significa escuchar y expresar libremente las propias opiniones. Y un diálogo intercultural, interreligioso pero, también, y quizás sobre todo, "intrarreligioso", porque cuando Huntington advirtió de la posibilidad del "choque" entre el islam y el cristianismo, lo hizo de manera interesada, dijo lo que querían que dijera y complacía los oídos de los magnates de los Estados Unidos y de sus presidentes republicanos. Hoy está claro que lo más apremiante es dirimir los conflictos que existen entre las diferentes facciones religiosas, especialmente en el islam: los sunitas, los chiitas, los salafitas, entre otros.

Hasta ahora, los grandes líderes del neoliberalismo han considerado que las actividades para alcanzar sus ambiciones geoestratégicas y económicas a cualquier precio (hasta la dolosa infracción de todas las pautas establecidas para invadir Iraq en el año 2003) quedaban impunes, porque la inmensa mayoría de los ciudadanos permanecía silenciosa.

Y, además, se distrae, se intenta utiliza la inmensa fuerza mediática para uniformizar, para que muchas personas compensen la desafección política mediante la pertenencia obsesiva y abusiva a clubes e instituciones deportivas. Pero todo eso durará poco tiempo. La corrupción, el desarraigo ético que caracteriza a tantos profesionales de la política que se convierten en palmeros, en aplaudidores en lugar de parlamentarios dispuestos a reforzar, a mejorar la representación y participación política, les irán desacreditando y será la voz de la gente la que prevalezca.

Repasemos la historia. Revisemos lo que ha sucedido para que se repita lo que debe repetirse y que nunca más acontezca lo que nunca debió haber tenido lugar. Tengamos presente todos los días, para nuestro comportamiento cotidiano, el ayer que es imprescindible para decidir acertadamente los caminos del mañana. "La calidad de un pintor, dijo Pablo Picasso, depende de la cantidad de pasado que lleve consigo". Pasado consciente. Pasado cierto para contribuir a dar a las alas de la juventud la fuerza que les faculte para el alto vuelo.

\section{Derribando muros, construyendo puentes}

Derribando muros con la fuerza de la transparencia, de la claridad conceptual, de la facultad creadora, de la serenidad, de la ponderación, de la aplicación permanente de los "principios democráticos" de la justicia, libertad, igualdad y solidaridad para el establecimiento progresivo de un nuevo marco de acción con la constante participación ciudadana. Que nadie se engañe: no van a seguir indignados, oprimidos, silenciosos. Si no hay evolución, habrá revolución. Si no hay acuerdo, habrá ruptura. Y esto es lo que hay que evitar a toda costa. Este porvenir luminoso en que todos los seres humanos y no solo unos cuantos puedan vivir dignamente, requiere que, esta vez sí, sean "los pueblos" los que decidan su propio futuro.

Para derribar muros y construir puentes es imprescindible el establecimiento de mecanismos muy rápidos y consistentes para que la justicia, especialmente en algunos casos, sea rápida y eficiente. Y que se pongan en práctica las grandes prioridades sociales a escala mundial: alimentación para todos; acceso al agua potable; servicios de salud de calidad; cuidado del medio ambiente; educación para todos a lo largo de toda la vida. El resultado es la paz. "La paz es un comportamiento", se declaró en Yamassoukro en 1989, cuando se puso en marcha el gran programa transversal de la UNESCO sobre Cultura de Paz y no Violencia. No hay paz sin justicia. No hay paz sin desarrollo humano. No hay paz sin igualdad. La paz es incompatible con la discriminación y la arbitrariedad.

Decía José Saramago que "lo peor de la paciencia es que puede ser infinita". Por tanto, paciencia sí, pero con límites bien señalados. Hay muchos imposibles hoy que pueden ser posibles mañana. Me gusta repetir la frase de unos escaladores que manifestaron "lo conseguimos porque no sabíamos que era imposible". Imaginación, audacia, conocimiento.

Análisis en profundidad, serenidad y firmeza para saber decir que "no" cuando, con la perentoriedad que lo han hecho recientemente los mercados, se induce a los políticos, con un acoso inaudito e inadmisible, a tomar decisiones que nunca deberían adoptar. 
Sé por experiencia que decir "no" cuando señalan y obligan a recorrer senderos improcedentes, no sólo origina una enorme satisfacción y tranquilidad de conciencia sino que, en general, las amenazas se desvanecen y quedan al descubierto las intolerables razones de la coacción.

Como explica Ramonet en el periódico La Jornada de México (2014), el martes 28 de octubre ha sido una jornada histórica. Primero, porque no es frecuente que el Papa convoque en El Vaticano un Encuentro Mundial de Movimientos Populares; segundo, porque es menos frecuente aún, que el Papa se dirija directamente a ellos, diciéndoles que quiere escuchar "la voz de los pobres porque los pobres no se conforman con padecer la injusticia sino que luchan contra ella" y, en un gran canto a la solidaridad, añade: "El Papa os quiere acompañar en esta lucha". Y ello se debe a que "los pobres ya no esperan de brazos cruzados soluciones que nunca llegan; ahora los pobres quieren ser protagonistas para encontrar ellos mismos una solución a sus problemas. "Espero que el viento de la protesta se convierta en vendaval de la esperanza. Todo esto ocurre cuando se saca al ser humano del centro del sistema, en el cual se halla ahora el dinero. Por eso hay que alzar la voz", ha repetido.

\section{La democracia es la solución}

En la década de los ochenta se aceptó sustituir los principios democráticos por las leyes mercantiles. Ahora, el poder se aleja de Occidente y las batallas que hay que ganar no son económicas sino, sobre todo, políticas. "Ni un día más de rodillas. Ni un día más acosados por los mercados. La política debe alzarse", escribía en 2011. Después de enumerar las medidas más urgentes en los distintos niveles, concluía diciendo que "una Declaración Universal de Democracia" sería especialmente oportuna" ya que sólo en este contexto es previsible el pleno ejercicio de los derechos humanos. La única solución es una democracia genuina a escala global y local. Y la democracia no se otorga ni se impone. No se construye desde arriba sino desde abajo, con la participación ciudadana.

\section{Democracia internacional}

Es necesario, con apremio, restablecer un multilateralismo democrático, terminando de una vez con los infructuosos y discrecionales "grupos oligárquicos" impuestos por el neoliberalismo globalizador. Con unas Naciones Unidas fuertes y dotadas de la integridad moral y formal que se requiere, la invasión de Irak, como he apuntado antes, no hubiera tenido lugar; la "primavera árabe" se hubiera encarrilado de la manera apropiada; el desarme nuclear sería ya, seguramente, una realidad y se habría terminado la impunidad que a escala supranacional tienen actualmente las mafias traficantes de armas, drogas y personas; la Organización Mundial del Comercio no se hallaría fuera de su ámbito y las ayudas para el desarrollo sostenible y humano se hubieran incrementado, las prioridades mundiales (alimentación, agua potable, servicios de salud, y educación) se hubieran, sin duda, puesto en práctica sucesivamente. La atención al medio ambiente, urgente responsabilidad intergeneracional, no sería motivo de alarma y acción impostergable como sucede actualmente.

Objetivos perentorios para completar, encauzar o recomponer, desde un nuevo Sistema de las Naciones Unidas (Mayor, 2012b), la presente situación y tendencias: favorecer el excelente curso de emancipación que se está produciendo en América Latina; en la Unión Europea (Richardson, 2010), sería preciso adoptar Tratados de unión política y económica que completarían la actual unión monetaria; difundir y poner en práctica en toda Europa la excelente Carta de Derechos Fundamentales de Europa (2000) e "inventar" la nueva Europa ratificándola como gran potencia creadora, solidaria y torre de vigía (Mayor, 2011b); contribuir a la "transparencia" de China y a su rápido progreso hacia un sistema de libertades públicas [una adecuada evolución de China -en los aspectos éticos, sociales, estructurales, medioambientales- es esencial para la nueva era (Ríos, 2014)]; en África, promover la consolidación del panafricanismo para que este importantísimo continente pueda, por fin, ocupar en el concierto internacional el prominente lugar que le corresponde; prestar especial atención a la India, fantástico país, ejemplo de democracia en circunstancias muy complejas; coordinar las acciones en caso de catástrofes naturales o provocadas; evitar, mediante "injerencia de interposición", la violación masiva de Derechos Humanos en casos como Camboya y Ruanda, o cuando la inexistencia de representantes del pueblo y de interlocutores a escala internacional hace necesaria la presencia de los cascos azules, como en Somalia, por ejemplo... 
Es muy preocupante, a escala mundial, el rearme de Japón y China, fomentado, como sucede habitualmente, por los grandes productores de armamento. $\mathrm{Y}$-vuelvo a insistir en ello, porque es una pieza esencial de la construcción de un porvenir distinto- es apremiante la refundación de unas Naciones Unidas dotadas de los medios de toda índole necesarios para arbitrar los grandes procesos que están en juego, o que lo estarán en breve plazo.

Referido al medio ambiente, lo primero que debe hacerse es limitar el inmenso poder de las grandes empresas "energéticas". Las energías renovables deben fomentarse, estudiándose en profundidad. En cuestiones potencialmente irreversibles, sería totalmente irresponsable seguir, como hasta ahora, mirando hacia otro lado.

A escala nacional, favorecer que países como España, de gran diversidad cultural, adopten sistemas que hagan plenamente compatibles sus diferencias de todo orden con un unánime respeto a los "principios democráticos", que proporcionan la necesaria cohesión del con-junto, como sucede en los sistemas federales o confederales.

La democracia es evolutiva y debe reconocer en cada momento histórico las características tanto conceptuales como "físicas" (entorno ecológico, por ejemplo), a las que no sólo debe adaptarse sino anticiparse. Hoy está claro que es necesario un nuevo concepto de trabajo y de tiempo y espacio laborales. Y un nuevo mapa energético mundial...

Entre las propuestas que he formulado a escala global, regional y nacional (Mayor, 2013) destaca impedir la evasión fiscal; supresión inmediata de los paraísos fiscales; tasas sobre las transacciones informáticas; estricta regulación de las "máquinas bolsas y relocalización industrial.

Y, sobre todo, el fomento, a todos los niveles, de una democracia genuina. La Declaración Universal de la Democracia tiene capítulos dedicados a democracia social, democracia política, democracia económica, democracia cultural e internacional. Es especialmente importante destacar el artículo undécimo en el que se subordinan todas las dimensiones y aspectos de la democracia económica a la justicia social. Se dice que el orden de los factores no altera el producto. Esto no es cierto en el caso de los aspectos sociales y económicos. La Comisión ECOSOC, de las Naciones Unidas, se ha detenido siempre en lo económico y muy pocas veces se han abordado los aspectos sociales. A los 50 años de existencia de las Naciones Unidas, en 1995, nunca se había celebrado una reunión sobre desarrollo social. Se organizó en Copenhague, en aquel momento, y se concluyó la reunión con ocho grandes "compromisos". Pero el neoliberalismo impidió que los aspectos sociales prevalecieran.

Otros aspectos muy importantes de la democracia son la justicia universal, la ciudadanía mundial, la conciencia permanente del destino común. Es muy urgente que se establezcan, para su estricto cumplimiento a escala planetaria, las leyes que permitan el comportamiento adecuado a los diferentes niveles, con el fin de que las grandes exigencias de una vida digna para todos los seres humanos sean una pronta realidad. "¿Quién sino todos?" escribió el gran poeta catalán Miquel Martí i Pol. Tenemos que ser todos. El tiempo de las disparidades, de las desigualdades lacerantes ha concluido porque, en el antropoceno, pueden alcanzarse puntos de no retorno que serían igualmente negativos para todos, con independencia del lugar de origen y el "estatus" social. Todos considerando la democracia como conducta cotidiana, como norma y pauta de vida. Como antes mencionaba, la democracia no se otorga ni se impone.

Hace unos años, en Un mundo nuevo escribía: “CCómo conciliar la adecuada conservación de la biosfera y el desarrollo de la socio-esfera? ¿Quién nos transmitirá la sabiduría ecológica? ¿Quién nos indicará los caminos d e otro desarrollo más equilibrado y más Solidario?". El desarrollo sostenible y humano es, está claro, el mejor camino hacia la convivencia pacífica (Mayor, 2000).

\section{"El otro mundo posible": tener presente el futuro}

Por primera vez en la historia, el ser humano se encuentra en condiciones de inventar nuevas fórmulas de convivencia si quiere sobrevivir como especie. Esta modificación global de 
las condiciones de vida ofrece nuevas posibilidades $y$, al mismo tiempo, obliga a afrontar dificultades hasta ahora desconocidas. Los problemas que afectan en la actualidad a una parte de la humanidad amenazan con transformar en breve plazo a todo el planeta. Con el desarrollo científico, pero también con su aplicación a la destrucción masiva, hoy más que nunca, el porvenir de cada ser humano, cuales quiera sean su raza o su religión, está estrechamente relacionado al de todos sus semejantes.

La ignorancia y la pobreza extrema; el fanatismo racial, religioso o ideológico; la intolerancia y el desdén hacia el prójimo; la desigualdad y la injusticia son fuente de violencia. Son estas las situaciones humanas que conducen a la marginación, la indiferencia, el rencor y la animadversión. Para atajar los conflictos en sus inicios, es menes-ter identificar estas raíces profundas y actuar a tiempo. La anticipación y la prevención que de ella puede resultar, constituye la victoria máxima, la que está a la altura de las facultades distintivas de la especie humana.

La revolución de la informática ha dado lugar a una nueva relación entre trabajo, capital y tecnología. “¿Cómo se regulará el mercado laboral -se pregunta Diego Beas (2014)- en una era de procesos pro-ductivos automatizados?". La disfunción provocada por Google en el mundo de la información y la publicidad; por Apple en la telefonía móvil y la música; por Amazon en los libros y la distribución de productos, siempre requiriendo muy pocos empleados si se compara con grandes empresas "tradicionales", debe analizarse con gran atención $\mathrm{y}$, aunque sean muchos los "hábitos" que deban transformarse radicalmente, es preciso favorecer el uso ponderado de las tecnologías que son ya pilar indispensable de "la nueva era".

Con los asesoramientos oportunos, "los pueblos" harán respetar, a través de una participación activa y constante, las raíces y tronco de la democracia "llamando a las cosas por su nombre", siendo ciudadanos y no súbditos.
A este respecto, hay que llamar la atención sobre una "competitividad" alcanzada por mano de obra altamente cualificada y extremadamente barata en lugar de por el talento, por las patentes, por el fomento del I+D+i. En el nuevo contexto, serán el conocimiento y la creatividad humana los que permitirán, en un marco laboral y productivo muy distinto, proporcionar los grandes trazos de una vida digna de ser vivida.

Sí, inventar el porvenir porque está por hacer. Hoy contamos con algo tan importante como es la experiencia, que debe ser solidaria, proporcional al extraordinario incremento de la longevidad. Es un tesoro inexplorado que ahora, también, por fin, puede contribuir a cambios radicales a todas las escalas. Ya no nos dirán "esto es imposible", "esto no tiene remedio". Ahora ya todos seremos conscientes de que tenemos que aprender a mirar, observar y reflexionar de otra manera. Y sacar partido de la experiencia y solidaridad acumulada a lo largo de tantas vidas.

Edgar Morin (1999) ha escrito sobre este proceso que hoy, gracias a la participación ciudadana, puede acelerarse. En cuanto hay semillas, en cuanto hay surcos para plantarlas aún a contraviento, aparecen los catalizadores que pueden esclarecer tantos horizontes hoy sombríos.

En "Humanismo: inventar el futuro" (Mayor, 2014a), destaco mi con-fianza en que la humanidad, con conciencia global, con igualdad de género y capacidad de expresarse, tomará en sus manos las riendas de su destino y eliminará la gobernanza que ha sustituido los valores universales por los intereses económicos. El siglo XXI será la era de la rebelión en el ciberespacio, preámbulo de liberad y de la igual dignidad de todos.

Sí, inventar el por-venir porque está por-hacer. Es preciso actuar en virtud de las propias reflexiones. Gorbachev, uno de los hombres más poderosos de la tierra en un momento determinado, supo actuar según su conciencia. Hoy, 25 años después de la caída del Muro de Berlín, proclama el poder de la sociedad civil y la importancia permanente de la libertad de expresión 
y de prensa, y la influencia indiscutible del internet, del ciberespacio. Las generaciones venideras necesitan ejemplos como los de un nonagenario -Stephan Hessel - y un octogenario -Mikhail S. Gorbachev- que han moviliza-do a la juventud hacia los rumbos del mañana.

He aquí algunos párrafos especialmente relevantes del discurso del Presidente Mikhail Gorbachev en Berlín el 9 de noviembre de 2014, con motivo del 25 Aniversario de la caída del Muro:

"Los acontecimientos de los últimos meses son la consecuencia de políticas miopes, de tratar de imponer los criterios de una parte ignorando los de las otras. En lugar de devenir el líder del cambio en un mundo global, Europa se ha convertido en arena de disputas políticas, de competición de esferas de influencia y de conflicto militar. Si esto continúa, Europa podría ser gradualmente irrelevante a escala internacional.

Reunirse, escucharse los unos a los otros. Es precisa una gran voluntad política para actuar de este modo y elaborar conjuntamente las prioridades de acción. Diálogo, diálogo, para, juntos, asegurar el futuro. El futuro es lo único que importa. Es urgente activar la cooperación para abordar los desafíos globales: extremismo, pobreza, desigualdad, medio ambiente, emigración,... Los retos globales, tan distintos como son, tienen todos un esencial aspecto común: ¡ninguno de ellos tiene solución militar!”
Corresponde ahora a la comunidad científica, académica, intelectual, en suma, contribuir a movilizar y dar sentido a tantos súbditos que, progresivamente, se convertirán en ciudadanos plenos. Si Europa no reacciona, la "cultura de la democracia" llegará del sur.

Los líderes políticos de hoy siguen sin darse cuenta de que el pueblo ya ha dejado de ser audiencia silenciosa, obediente y temerosa. Ahora ya puede expresarse. Lo que hay que hacer es cambiar de brújula, para no sorprenderse cada vez que fenómenos como el de "Podemos" resaltan la monotonía que ha prevalecido en el pasado: el futuro no es el que se esperaba.

Cada ser humano único capaz de pensar, de crear: esta es la esperanza, el eje y fundamento del futuro que soñamos. Por esta razón es tan importante la filosofía. Y es tan importante la longevidad que permitirá, bien utilizada, disponer -como ya he indicado- de un cúmulo de experiencias disponibles para los más jóvenes.

Sembrar! Es indispensable plantar, cada día, semillas que proporcionen ubérrimas cosechas para los habitantes del mañana. Es tiempo de acción. De compromiso personal. Decía José Luis Sampedro, y así concluyo: “Este ocaso es el momento de la acción entre todos por-que otro mundo no sólo es posible, es seguro".

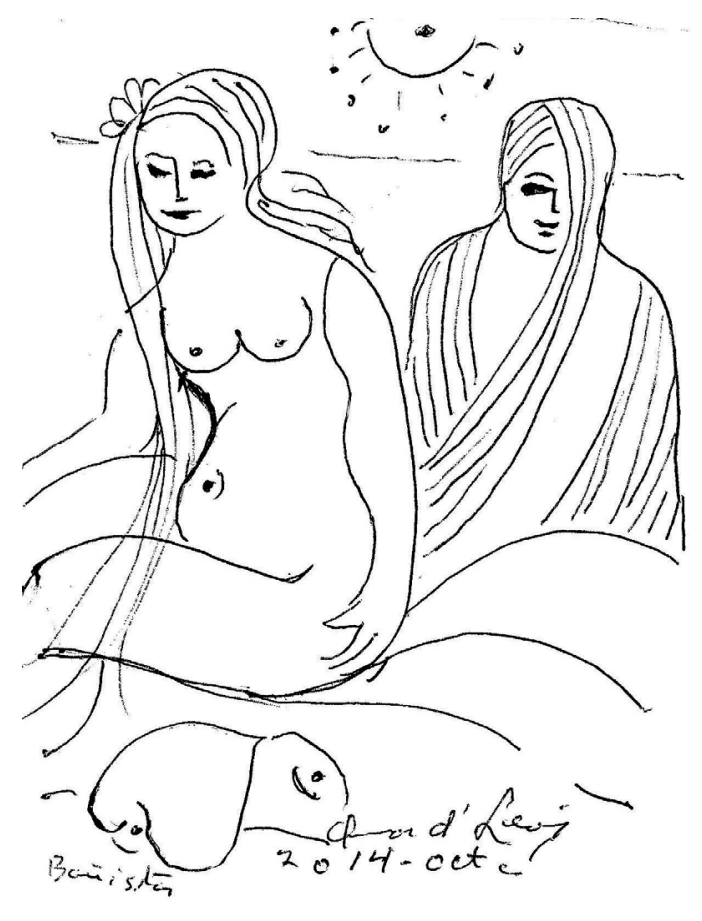

